\title{
The Effect of Coloring Beverages on Color Stability of Hybrid Ceramics with Different Surface Treatments
}

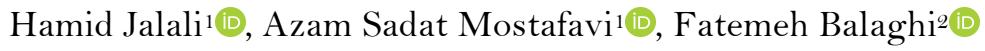

${ }^{1}$ Dental Research Center, Department of Prosthodontics, School of Dentistry, Tehran University of Medical Sciences, Tehran, Iran. ${ }^{2}$ Private Practice, Tehran, Iran.

Correspondence: Azam S. Mostafavi, Department of Prosthodontics, School of Dentistry, Tehran University of Medical Sciences, North Kargar Ave, Tehran, Iran Po. Code: 14399-55991. E-mail: as-mostafavi@sina.tums.ac.ir

\section{Academic Editor: Myroslav Goncharuk-Khomyn}

Received: 18 February 2021 / Review: 28 May 2021 / Accepted: 28 July 2021

How to cite: Jalali H, Mostafavi AS, Balaghi F. The effect of coloring beverages on color stability of hybrid ceramics with
different surface treatments. Pesqui Bras Odontopediatria Clín Integr. 2022; 22:e210044.
https://doi.org/10.1590/pboci.2022.001

\begin{abstract}
Objective: To assess the effects of coloring beverages on the color stability of two types of hybrid ceramics with different surface treatments. Material and Methods: 180 specimens of two hybrid ceramics (Vita Enamic and Mazic Duro) and a feldspathic ceramic (Vita Mark II) were prepared ( $n=60$ in each group). Half of the discs in each group were glazed while the other was polished. The specimens were then divided into three subgroups and immersed in distilled water, carrot juice, and coffee. The overall color difference $(\Delta \mathrm{E})$ was calculated based on CIE L*a*b* color space. Data were analyzed using three-way and one-way ANOVA; Tukey's honest significant difference was also done for pairwise comparisons $(\alpha=0.05)$. Results: Vita Mark II specimens revealed less overall color changes compared to other groups. The $\Delta \mathrm{E}$ of the glazed Vita Enamic specimens was greater than polished specimens following immersion in distilled water $(p=0.03)$ and coffee $(p=0.001)$, but it was not significant for carrot juice. The same results were obtained for polished Mazic Duro specimens. Relatively similar amounts of $\Delta \mathrm{E}$ were recorded in polished and glazed subgroups of Vita Mark II. Conclusion: The $\Delta \mathrm{E}$ of hybrid ceramics was higher than Vita Mark II. Polishing could be recommended for surface treatment of hybrid ceramics instead of glazing, saving time and facilitating the process.
\end{abstract}

Keywords: Ceramics; Dental Porcelain; Spectrophotometry; Color; Beverages. 


\section{Introduction}

Esthetic restorations are among the highly popular dental treatments. Different restorative materials may be used for the fabrication of esthetic restorations, such as different types of reinforced composite resins, conventional ceramics, and high-strength reinforced ceramics [1]. Dental ceramics are ideal for restoring natural teeth due to their excellent physical properties, favorable esthetics, optimal biocompatibility, low thermal conduction, and high wear resistance [2]. Thus, ceramics have numerous applications for dental restorations such as inlays, onlays, crowns, and porcelain veneers [3]. In addition, esthetic ceramic crowns should be able to preserve their morphology and optical and biological properties under different clinical conditions [4].

The computer-aided design/computer-aided manufacturing (CAD-CAM) technology has been used in cosmetic dentistry for the past 30 years, enhancing the fabrication of restorations. Also, under controlled conditions, the fabricated CAD-CAM blocks increase the internal strength of restorations compared with the conventional fabrication methods [5].

Recently, hybrid resin ceramics were introduced for the CAD-CAM systems, decreasing all-ceramic restorations' fragility under functional loads. These materials include hybrid ceramics with resin-infused matrix (Enamic, Vita Zahnfabrik), resin nano-ceramics (Lava Ultimate, 3M ESPE), and nano-hybrid ceramics (Cerasmart, GC Dental Products) [1,6].

Vita Enamic possesses a combination of ceramic and composite properties. It contains $86 \mathrm{wt} \%$ nanofeldspathic ceramic composed of silicon oxide, aluminum oxide and $14 \mathrm{wt} \%$ methacrylate polymer. Due to the ceramic and polymer dual network, the manufacturer claims that it has lower brittleness and fragility than ceramics and possesses excellent mechanical properties and optimal integrity [7]. In this material, the dominant ceramic network is reinforced by a polymer network, such that the two networks are interconnected. Despite having a high degree of elasticity, it can tolerate high loads after bonding; therefore, it can be used in areas with minimal preparation. Resistance to staining in crowns is as important as their fracture resistance and other mechanical properties. Over time, poor color stability and staining of crowns often necessitate crown replacement. On the other hand, restorations with rougher surfaces are more susceptible to staining. Therefore, the finishing and polishing techniques should provide smooth restoration surfaces with light reflection properties comparable to those of natural teeth [8].

Some studies reported that glazing provides better surface properties and stain resistance than polishing techniques $[9,10]$. On the other hand, it has been reported that polishing has displayed promising results similar to glazing $[6,8]$. Evidence shows that satisfaction with the color and appearance of teeth has positive psychological impacts on patients of all age groups [11,12].

In restorative dentistry, dental esthetics depends on selection of a durable biomaterial with favorable color stability [13]. The color parameters can be quantitatively measured by a spectrophotometer according to the CIE L*a*b* color space, an analytical model for color differentiation of human eye. The main advantage of this system over other colorimetric systems is the ability of clinical interpretation of results because the color change in this system is perceivable by the human eye and accordingly, the range of detectable color change can be clinically specified [14].

Since studies about the effects of coloring solutions on hybrid ceramics and their stain resistance are scarce with different conditions, this in vitro study sought to assess the effects of different coloring beverages on the stainability of hybrid ceramics with two different surface treatments (polishing and glazing). The null 
hypothesis was that there would be no significant difference in a color change of ceramic specimens with different surface treatments following immersion in different coloring beverages.

\section{Material and Methods}

Sampling

A power analysis was performed based on a previous study by Kilinc and Turgut [8]. The sample size was calculated as 10 specimens per group for a significance level of $\alpha=0.05$ and power of 0.80 .

Fabrication and Preparation of Specimens

Table 1 presents the characteristics of CAD-CAM ceramic blocks used in the present study. All the specimens were in the same A2 shade. The CAD-CAM blocks were mounted in related molds with polyester material and were then sectioned into 1-mm-thick slices using a cutting machine (T210 Mecatome, PRESI Trade, Shanghai, China). A digital caliper (Guanglu Instruments, Guilin, China) was used to confirm the thickness of specimens. Sixty discs of each kind of CAD-CAM ceramic were prepared and stored in plastic containers.

Table 1. Description of materials used in this study.

\begin{tabular}{|c|c|c|c|c|c|}
\hline Group & Material & Composition & Manufacturer & $\begin{array}{c}\text { Specimen's } \\
\text { Dimension }(\mathrm{mm})\end{array}$ & Batch \# \\
\hline 1 & $\begin{array}{c}\text { Vita Enamic } \\
\text { (Hybrid ceramic) }\end{array}$ & $\begin{array}{l}86 \% \text { feldspar ceramic enriched with } \\
\text { aluminum oxide, } 14 \% \text { UDMA + } \\
\text { TEGGDMA }\end{array}$ & $\begin{array}{l}\text { VITA Zahnfabrik, Bad } \\
\text { Sackingen, Germany }\end{array}$ & $1 * 12 * 14$ & 60210 \\
\hline 2 & $\begin{array}{c}\text { Mazic Duro (Nano } \\
\text { hybrid ceramic }\end{array}$ & $\begin{array}{l}20 \% \text { Resin matrix (UDMA + } \\
\text { TEGGDMA) and } 80 \% \text { Ceramic } \\
\text { Filler (barium aluminosilicate, } \\
\text { silicon dioxide and zirconia). }\end{array}$ & $\begin{array}{c}\text { Vericom, Chuncheon, } \\
\text { Korea }\end{array}$ & $1 * 12 * 12$ & DH7No2A 3 \\
\hline 3 & $\begin{array}{l}\text { Vita Mark II } \\
\text { (Feldspathic } \\
\text { ceramic block) }\end{array}$ & $\begin{array}{l}\text { Feldspathic crystalline particles in } \\
\text { glassy matrix (filler: 30\% Fine } \\
\text { particle feldspar ceramic; } 54 \%-64 \% \\
\mathrm{SiO}_{2}, \quad 20-23 \% \text { Al2O3, } 6 \%-9 \% \\
\mathrm{Na} 2 \mathrm{O}, 6-8 \% \mathrm{~K} 2 \mathrm{O} \text { ) }\end{array}$ & $\begin{array}{l}\text { VITA Zahnfabrik, Bad } \\
\text { Sackingen, Germany }\end{array}$ & $1 * 12 * 14$ & 36990 \\
\hline
\end{tabular}

Glazing of Specimens

Half of the ceramic discs in groups $1(n=30)$ and $2(n=30)$ were glazed using Optiglaze liquid (Nanofilled light-cured protective coating, GC, Tokyo, Japan). The specimens were then light-cured for $30 \mathrm{~s}$ using a dental lab curing unit (Heraflash Light Curing Unit, Heraeus Kulzer GmbH., Germany). In group 3, SpeedGlaze (Glaze spray, Dentsply Sirona, North Carolina, USA) was sprayed on half of the specimens $(n=30)$ and they were then placed in Cerec SpeedFire furnace (Dentsply Sirona, North Carolina, USA) at $850^{\circ} \mathrm{C}$ for 1 $\min$.

Polishing of Specimens

The remaining half of ceramic discs in groups 1 and 2 were polished with Enamic polishing kit (VITA Zahnfabrik H. Rauter GmbH \& Co. KG, Bad Säckingen, Germany) as follows: Step 1: Pink-color pre-polishing burs were used for 7-10 min; Step 2: Gray-color high gloss polishing burs were used for 5-8 min.

The remaining half of the specimens in group 3 were polished with 60,600, and 1200-grit silicon carbide paper discs (Cosmedent Inc., Chicago, IL, USA) in an orderly fashion to obtain a high-shine surface. Next, the specimens in polished and glazed groups were randomly divided into three subgroups $(n=10)$ for 
immersion in distilled water (control subgroup), coffee, and carrot juice (experimental subgroups). Figure 1 shows the study groups. The specimens were then immersed in the respective coloring solutions in coded plastic containers and incubated at $37^{\circ} \mathrm{C}$ for a month. The solutions were not diluted and replaced every three days to prevent possible bacterial contamination.

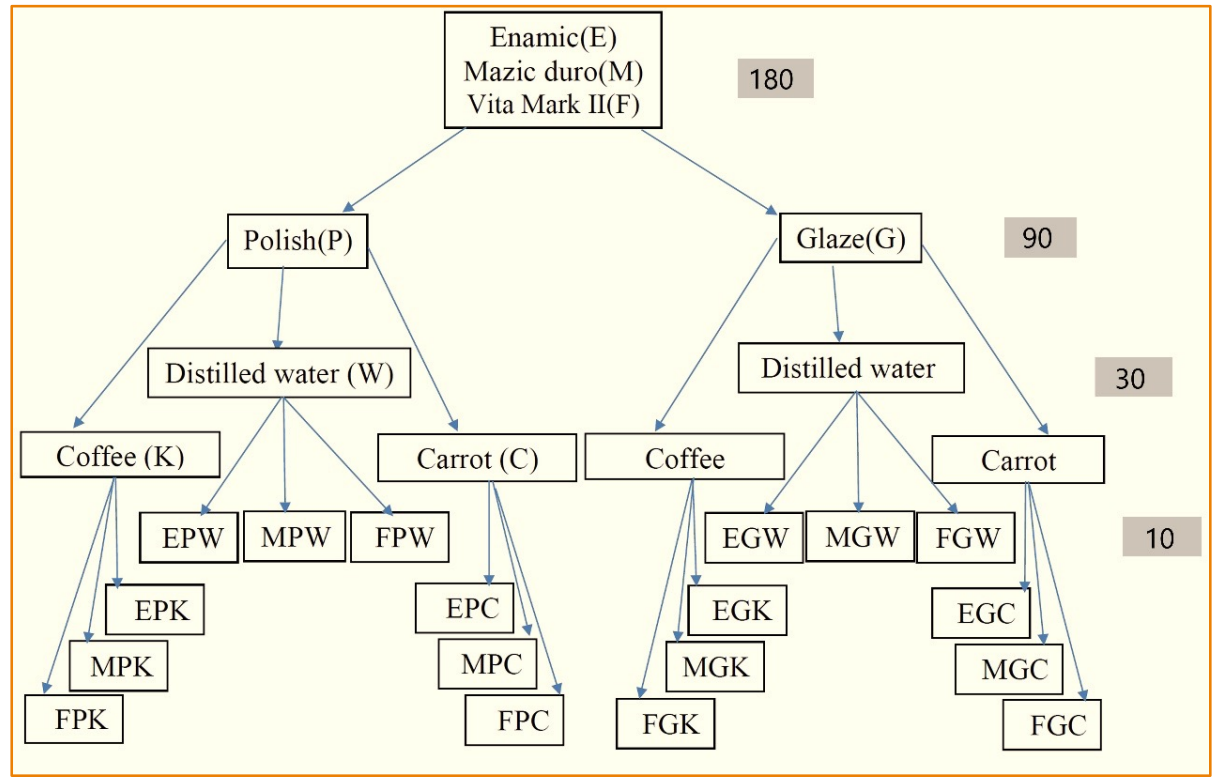

Figure 1. Study groups and their subgroups.

Spectrophotometry

The specimens were immersed in distilled water in an ultrasonic bath for 5 min to ensure no contamination prior to spectrophotometry. The color difference $(\Delta \mathrm{E})$ of the specimens after immersion (compared with baseline) was measured using a portable spectrophotometer (X-Rite I1-Pro, X-Rite, Grand Rapids, USA). The spectrophotometer was calibrated with a white tile prior to measurements and it was repeated once every hour. The color parameters of the specimens were measured by the same operator under standardized environmental conditions. Since the specimens were semi-transparent, the light emitted by the spectrophotometer could be passed through the margins. To prevent this effect (edge-loss) which could be related to the position of spectrophotometer aperture relative to the specimen, three measurements were performed at the center of each specimen. The mean of the obtained three values was then calculated and reported. Visual thresholds will be used for the analysis of the results; the color change cannot be detected by the human eye under normal conditions when $\Delta \mathrm{E}<1$. Furthermore, $\Delta \mathrm{E}>3.3$ is not clinically acceptable. In addition, for standardization of the background color effect on the color parameters, white cardboard (Leneta Co., Mahwah, NJ, USA) was used as the background. The spectrophotometric data were interpreted using Xrite i1 Share software (v1.4, X-Rite Inc., Grand Rapids, MI, USA).

A total of 894 measurements were made, which decreased to 298 measurements after calculating the mean values. The CIE $\mathrm{L}^{*} \mathrm{a}^{*} \mathrm{~b} *$ color system [15] was used to calculate the $\Delta \mathrm{E}$ of ceramic specimens in different groups based on the type of surface treatment and type of coloring solution.

\section{Data Analysis}

Data were analyzed using SPSS software (version 22, IBM Co, New York, USA). The measures of central dispersion (mean, standard deviation, minimum and maximum) of $\Delta \mathrm{E}$ were calculated and reported 
separately based on the type of ceramic (feldspathic porcelain, Vita Enamic, and Mazic Duro), type of surface treatment (glazing and polishing), and type of coloring solution (distilled water, carrot juice, and coffee). Three-way ANOVA was applied to assess the effects of type of ceramic, coloring solution, and type of surface treatment on $\triangle \mathrm{E}$. One-way ANOVA was used to compare the color change based on the type of ceramic and type of coloring solution. The Student's t-test was applied to compare the color change based on the type of surface treatment. Pairwise comparisons were carried out using the Tukey honestly significant difference (HSD) test $(\alpha=0.05)$.

\section{Results}

The effects of coloring solution $(\mathrm{p}=0.009)$, type of ceramic $(\mathrm{p}<0.001)$ and type of surface treatment $(\mathrm{p}<0.001)$ as well as the interaction effects of coloring solution and type of ceramic $(\mathrm{p}=0.04)$ and type of ceramic and type of surface treatment $(\mathrm{p}<0.001)$ on $\Delta \mathrm{E}$ were statistically significant. However, the interaction effects of the type of coloring solution and type of surface treatment $(p=0.347)$, and type of coloring solution, type of ceramic, and type of surface treatment $(\mathrm{p}=0.35)$ on $\Delta \mathrm{E}$ were not significant (Table 2$)$.

Table 2. Statistical analysis of the ceramic type, coloring beverage and surface treatment on the color change of specimens.

\begin{tabular}{|c|c|c|c|c|c|}
\hline Source & Type III Sum of Squares & df & Mean Square & $\mathbf{F}$ & Sig. \\
\hline Media & 12.587 & 2 & 6.294 & 4.858 & 0.009 \\
\hline Material & 40.991 & 2 & 20.496 & 15.819 & 0.000 \\
\hline Polish & 46.299 & 1 & 46.299 & 35.735 & 0.000 \\
\hline Media * Material & 13.040 & 4 & 3.260 & 2.516 & 0.044 \\
\hline Media * Polish & 2.768 & 2 & 1.384 & 1.068 & 0.347 \\
\hline Material * Polish & 26.686 & 2 & 13.343 & 10.299 & 0.000 \\
\hline Media * Material * Polish & 5.806 & 4 & 1.452 & 1.120 & 0.350 \\
\hline
\end{tabular}

Vita Mark II specimens revealed less overall color changes than the other two groups (Figure 2). The $\Delta \mathrm{E}$ of the glazed Vita Enamic specimens was greater than that of polished specimens following immersion in distilled water (2.32 versus $0.60, \mathrm{p}=0.03$ ) and coffee (3.3 versus $0.58, \mathrm{p}=0.001)$; despite higher color change values recorded in carrot juice group, it was not significant $(\mathrm{p}>0.05)$. The same results were obtained for polished Mazic Duro specimens ( $\mathrm{p}=0.02, \mathrm{p}=0.01$ for coffee and distilled water, respectively). Relatively similar amounts of $\Delta \mathrm{E}$ were recorded in polished and glazed subgroups of Vita Mark II ( $>>0.05$ ). Vita Enamic displayed the same $\Delta \mathrm{E}$ for glazed specimens in different coloring solutions, likewise for polished ones $(\mathrm{p}>0.05)$. Higher levels of $\Delta \mathrm{E}$ were detected for polished Mazic Duro when immersed in carrot juice and coffee compared to distilled water $(\mathrm{p}<0.001$ comparing MPC and MPW), although glazed specimens in this group showed no significant differences $(\mathrm{p}>0.05)$.

Similar $\Delta \mathrm{E}$ values were recorded in glazed Vita Mark II specimens, while more color changes were detected for carrot juice and coffee compared to distilled water in polished ones ( $<<0.001$ for FPC and FPW, $\mathrm{p}=0.004$ for FPC and FPK) (Table 3). Among glazed specimens immersed in distilled water, $\Delta \mathrm{E}$ of Vita Enamic was greater than Vita Mark II ( $\mathrm{p}=0.01)$, while Mazic Duro specimens revealed no significant differences with other two groups (Table 3). Among glazed specimens immersed in coloring solutions, Vita Mark II displayed less color changes; for distilled water, the most color change was related to Vita Enamic, which was significantly different from the feldspathic specimens $(\mathrm{p}=0.01)$. In carrot juice, Mazic Duro disclosed greatest $\Delta \mathrm{E}$ with a significant difference to Vita mark II $(\mathrm{p}=0.01)$. In coffee, the most $\Delta \mathrm{E}$ was recorded for Vita Enamic 
following by Mazic Duro and both were significantly higher than the third group ( $\mathrm{p}=0.01$ and $\mathrm{p}=0.005$, respectively).

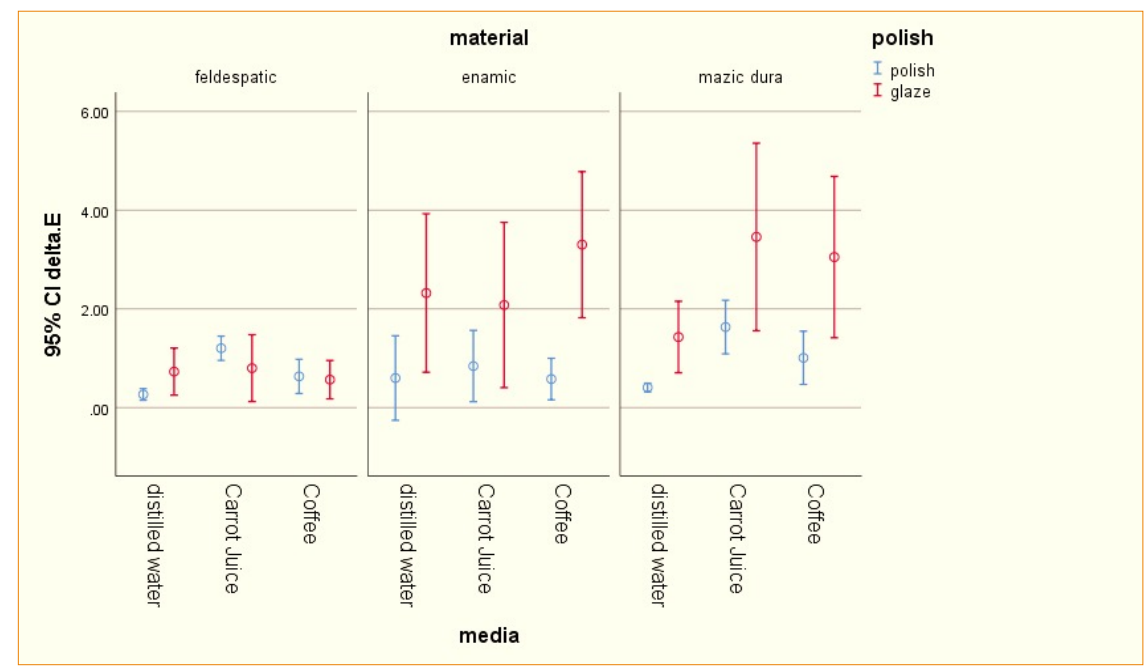

Figure 2. The mean color difference $(\Delta \mathrm{E})$ in terms of immersion solutions, surface treatment and ceramic type.

Table 3. The mean color difference $(\Delta E)$ and standard deviation of ceramic specimens with two different surface treatments, immersed in 3 types of coloring solutions.

\begin{tabular}{cccc}
\hline Ceramic & Surface Treatment & Coloring Solution & Mean \pm Std. Deviation \\
\hline Vita Enamic & Polished & Water & $0.60 \pm 0.69$ \\
& & Carrot Juice & $0.84 \pm 0.58$ \\
& Glazed & Coffee & $0.58 \pm 0.34$ \\
& & Water & $2.32 \pm 1.30$ \\
& Polished & Carrot Juice & $2.08 \pm 1.35$ \\
& & Coffee & $3.30 \pm 1.19$ \\
Mazic Duro & Water & $0.41 \pm 0.12$ \\
& \multirow{3}{*}{ Glazed } & Carrot Juice & $1.63 \pm 0.76$ \\
& & Coffee & $1.01 \pm 0.75$ \\
& Polished & Water & $1.43 \pm 1.01$ \\
& & Carrot Juice & $3.46 \pm 2.66$ \\
& & Coffee & $3.05 \pm 2.28$ \\
Vita Mark II & Water & $0.27 \pm 0.16$ \\
& \multirow{2}{*}{ Glazed } & Carrot Juice & $1.20 \pm 0.34$ \\
& & Coffee & $0.63 \pm 0.48$ \\
& & Water & $0.73 \pm 0.67$ \\
& & Carrot Juice & $0.80 \pm 0.88$ \\
& & Coffee & $0.57 \pm 0.54$ \\
\hline
\end{tabular}

\section{Discussion}

This study assessed the effects of coffee and carrot juice on the stainability of glazed and polished hybrid ceramics (Vita Enamic and Mazic Duro) compared to a control group (Vita Mark II feldspathic porcelain). The results showed a significant effect of the ceramic type and the interaction effect of coloring solution and ceramic type, as well as interaction effect of ceramic type and surface treatment on $\Delta \mathrm{E}$. Thus, the null hypothesis of the study, was rejected.

In general, the $\Delta \mathrm{E}$ of all ceramic specimens was within the clinically acceptable range, except for the glazed Mazic Duro specimens stored in carrot juice $(\Delta \mathrm{E}=3.46)$. Acar et al. [16] reported that Enamic was a 
suitable alternative to lithium disilicate ceramics in color stability. Considering the variable chemical composition of ceramics, they might have diverse optical behavior; the current results confirmed this statement.

Ceramics' surface quality and color change are influenced by their crystalline structure, polymer matrix, and size and shape of filler particles. In this study, Vita Mark II porcelain had lower $\Delta \mathrm{E}$ than Vita Enamic and Mazic Duro, which was in agreement with Abu-Obaid et al. [17] results. Vita Mark II is a feldspathic porcelain and the difference in type of ceramics is the main reason explaining their different color stability. Also, ceramics composed of more stable compounds experience more homogenous color change following immersion in different coloring solutions and after polishing and glazing surface treatments. Therefore, show higher color stability [8]. On the other hand, the manufacturers of hybrid ceramics claim that the fine-structure feldspar ceramic network is reinforced by the application of a completely homogenous polymer network [18].

The main idea was to achieve higher strength and Weibull modulus and minimal wear in antagonistic teeth in patients with bruxism. However, due to having a weak polymer matrix, it is easily separated from the ceramic network. Consequently, it results in higher surface roughness of hybrid ceramics, which adversely affects their optical properties in long-term [19]. Furthermore, evidence shows that Vita Enamic has high amounts of $\mathrm{Al}_{2} \mathrm{O}_{3}$ (about 23wt\%); therefore, it has lower translucency than Vita Mark II [19]. On the other hand, in addition to color parameters and composition of ceramics, their surface treatment also affects the optical properties of restorations such that high-gloss polishing improves the esthetic appearance of ceramic and composite restorations. Vita Enamic has reportedly higher internal and marginal adaptation than feldspathic ceramic; this superiority can be related to the better adaptation and compatibility of Vita Enamic with the CAD-CAM technology [20].

Considering the scarcity of studies on the novel hybrid ceramics, adequate information about the effects of finishing and polishing techniques or immersion in coloring solutions on their color stability is not available. The overall appearance and optical perception of dental restorations are influenced by several factors such as the color of the adjacent teeth, the effects of light scattering, and the inherent properties of materials such as their opacity and translucency. The color change cannot be detected by the human eye under normal conditions when $\Delta \mathrm{E}<1$. Furthermore, $\Delta \mathrm{E}>3.3$ is not clinically acceptable [21].

Kilinc and Turgut [8] showed that the optical properties of CAD-CAM materials were affected by the type of material. Also, the color stability of Vita Mark II ceramic was higher than that of polymer-based resin ceramics. Saba et al. [22] reported that the color change of Enamic was higher than that of Vita Mark II, and maximum staining occurred in coffee solution (in comparison to red wine and distilled water). Moreover, Lawson et al. reported that the color change of Enamic specimens was higher than that of Paradigm C (feldspathic porcelain) but not significant and it was clinically acceptable [23]. On the other hand, Koksal and Dikbas [24] evaluated the color stability of porcelain and acrylic teeth and reported that porcelain teeth had higher color stability. Furthermore, Acar et al. [16] and Gawriołek et al. [25] exhibited that ceramic materials have better color stability than composite resins. In the present study, the color stability of feldspathic porcelain was higher than that of Vita Enamic and Mazic Duro, which was in agreement with the results of the recent studies.

Similar to this study, Ghahramanloo et al. [26] showed that type of restorative material (GC Gradia indirect micro-ceramic composite and Vita VMK 95 porcelain), type of solution (orange juice, tea, and cola) and duration of storage had significant effects on color parameters. 
The current results revealed that the effect of surface treatment method and the interaction effect of ceramic type and surface treatment method on color change were statistically significant, such that glazed Vita Enamic and Mazic Duro specimens experienced greater $\Delta \mathrm{E}$ than polished specimens following immersion in different coloring solutions. However, polished and glazed feldspathic porcelain specimens experienced almost the same degree of $\Delta \mathrm{E}$ following immersion in coloring drinks. Polishing and glazing of ceramics had different effects on the $\mathrm{L}^{*}, \mathrm{a}^{*}$ and $\mathrm{b}^{*}$ color parameters such that polishing and glazing increased the color parameters in some ceramics and decreased them in some others; no definite conclusion has been reached on this topic. Glazing of ceramic in a porcelain oven is conventionally performed for surface treatment of ceramic restorations and achieving a smooth surface.

Manual polishing can also create a smooth ceramic surface comparable to glazing [27]. This study revealed that manual polishing, similar to glazing, created a homogenous surface in terms of color parameters of ceramics; however, the role of ceramic type in this respect is also important. Kilinc and Turgut [8] showed that manual polishing of ceramics could yield results comparable to glazing. In this regard, the same result was obtained in the present study for Vita Mark II ceramic. However, they recommend glazing to decrease the stainability of Enamic, which can be due to evaluation of specimens after aging (and not immersion in coloring solutions). Sagsoz et al. [6] evaluated the effect of polishing techniques on color stability of CAD-CAM resin ceramics and demonstrated that the use of polishing kits resulted in a color stability comparable to glazing of ceramic specimens with no significant difference between them. Moreover, Ozarslan et al. [28] reported superior clinical performance of translucent Vita Enamic in terms of color change following the use of a clinical polishing kit compared with a technical polishing kit and glazing. The authors immersed the same groups of specimens in coloring agents in another study and reported that polishing techniques were preferred for interpenetrating network (IPN) materials in terms of color stability [29].

In the present study, despite some differences in $\Delta \mathrm{E}$ of glazed and polished ceramic specimens, the results revealed that polishing kits provided a color stability comparable to glazing in ceramic specimens. Thus, manual polishing of ceramic restorations can be considered an alternative to glazing to obtain smoother and more uniform restoration surfaces. Saving time is the main advantage of manual polishing because there would be no need to send the restoration to a laboratory (as required for glazing). On the other hand, polishing after glazing decreases the lightness of specimens, removes the excess parts, and confers a more naturallooking appearance to the restoration [30].

However, some researchers have reported the superiority of glazing to polishing for porcelain ceramics in terms of surface properties and color stability [2,9,10,31]. In this regard, Abu-Obaid et al. [17] suggested re-glazing after surface adjustment instead of polishing. Although the color change of Vita Mark II was not significant between polished and glazed groups, which was in line with the present study, the stainability was higher in polished Enamic specimens. This difference in Enamic results could be due to different immersion times and also polishing procedures.

The current study results showed that the interaction effect of coloring solution and surface treatment and the interaction effect of coloring solution and ceramic material on $\Delta \mathrm{E}$ were significant; however, the interaction effect of coloring solution and surface treatment on $\Delta \mathrm{E}$ was not significant. The glazed feldspathic porcelain specimens showed almost equal color change following immersion in all three solutions; however, the polished specimens showed greater color change following immersion in carrot juice and coffee, compared with distilled water, which indicates the significant effect of type of coloring solution on $\Delta \mathrm{E}$. The glazed and polished Vita Enamic specimens showed almost equal $\Delta \mathrm{E}$ following immersion in different solutions, while the 
polished and glazed Mazic Duro specimens showed greater $\Delta \mathrm{E}$ following immersion in carrot juice and coffee, compared with distilled water. Several studies have shown the significant effects of different types of nutrients on $\Delta \mathrm{E}$ of dental restorations.

The color change following exposure to coloring solutions is an external color change that occurs due to the accumulation of stains on the surface or subsurface of restorations. For example, discoloration following consumption of coffee is due to deposition of melanoidins (brown macromolecular compounds) and for carrot juice, it is because of carotene (red-orange pigment). In general, staining following the consumption of coloring drinks more commonly occurs in acrylic denture teeth [32,33] and dental composites and porcelains rank next. The controversy and variability in the reported values for $\Delta \mathrm{E}$ of ceramics in different studies can be attributed to the use of different types of staining solutions, duration of immersion, instruments used for color measurement, type of materials and their thickness, and conduction of thermocycling or aging. Knowledge about the color change of restoration materials would help clinician in decision-making based on the existed scenario, such as the patient's diet, available time and the equipment.

This study had some limitations; artificial saliva was not used for immersion of specimens during the time intervals between their immersions in coloring solutions and the aging of ceramic specimens was not performed either. In addition, future studies are required to assess the efficacy of toothbrushing for elimination of stains from ceramic surfaces.

\section{Conclusion}

The color change of all ceramic specimens was within the clinically acceptable range, except for the glazed Mazic Duro ceramic specimens immersed in carrot juice. However, the color difference of Vita Enamic and Mazic Duro ceramics was higher than that of feldspathic porcelain. Considering the lower color change of polished specimens, polishing can be considered for surface treatment of hybrid ceramics instead of glazing, which facilitates the delivery process of the prosthesis.

\section{Authors' Contributions}

\begin{tabular}{|c|c|c|}
\hline HJ & (iD) https://orcid.org/0000-0003-1684-2846 & Conceptualization, Methodology, Writing - Review and Editing and Visualization. \\
\hline ASM & (i) https://orcid.org/0000-0002-6297-4797 & $\begin{array}{l}\text { Conceptualization, Methodology, Formal Analysis, Investigation, Writing - Original Draft and } \\
\text { Writing - Review and Editing. }\end{array}$ \\
\hline $\mathrm{FB}$ & (iD) https://orcid.org/0000-0003-1159-1021 & Formal Analysis, Investigation, and Writing - Review and Editing. \\
\hline
\end{tabular}

\section{Financial Support}

This study supported by Tehran University of Medical Sciences (Grant No: 99-2-133-48651).

\section{Conflict of Interest}

The authors declare no conflicts of interest.

\section{Data Availability}

The data used to support the findings of this study can be made available upon request to the corresponding author.

\section{References}

[1] Denry I, Kelly J. Emerging ceramic-based materials for dentistry. J Dent Res 2014; 93(12):1235-42. https://doi.org/10.1177/0022034514553627

[2] Yılmaz C, Korkmaz T, Demirköprülü H, Ergün G, Özkan Y. Color stability of glazed and polished dental porcelains. J Prosthodont 2008; 17(1):20-4. https://doi.org/10.1111/j.1532-849X.2007.00237.x 
[3] Conrad HJ, Seong W-J, Pesun IJ. Current ceramic materials and systems with clinical recommendations: a systematic review. J Prosthet Dent 2007; 98(5):389-404. https://doi.org/10.1016/So022-3913(07)60124-3

[4] Vieira AC, Oliveira MC, Lima EM, Rambob I, Leite M. Evaluation of the surface roughness in dental ceramics submitted to different finishing and polishing methods. J Indian Prosthodont Soc 2013; 13(3):290-5. https://doi.org/10.1007/s13191-013-0261-y

[5] El Zohairy AA, De Gee AJ, Mohsen MM, Feilzer AJ. Microtensile bond strength testing of luting cements to prefabricated CAD/CAM ceramic and composite blocks. Dent Mater 2003; 19(7):575-83. https://doi.org/10.1016/s0109-5641(02)00107-O

[6] Sagsoz O, Demirci T, Demirci G, Sagsoz NP, Yildiz M. The effects of different polishing techniques on the staining resistance of CAD/CAM resin-ceramics. J Adv Prosthodont 2016; 8(6):417-22. https://doi.org/10.4047/jap.2016.8.6.417

[7] VITA. No. 10025 VITA ENAMIC Technical and scientific documentation (Version 006). Available from: https://www.vita-zahnfabrik.com/en/Download-centre-Product-information-612.html. [Accessed on June 3, 2020].

[8] Kilinc H, Turgut S. Optical behaviors of esthetic CAD-CAM restorations after different surface finishing and polishing procedures and UV aging: An in vitro study. J Prosthetic Dent 2018; 120(1):107-13. https://doi.org/10.1016/j.prosdent.2017.09.019

[9] Motro PFK, Kursoglu P, Kazazoglu E. Effects of different surface treatments on stainability of ceramics. J Prosthetic Dent 2012; 108(4):231-7. https://doi.org/10.1016/So022-3913(12)60168-1

[10] Fuzzi M, Zaccheroni Z, Vallania G. Scanning electron microscopy and profilometer evaluation of glazed and polished dental porcelain. Int J Prosthodont 1996; 9(5):452-8.

[11] Davis L, Ashworth P, Spriggs L. Psychological effects of aesthetic dental treatment. J Dent 1998; 26(7):547-54. https://doi.org/10.1016/s0300-5712(97)00031-6

[12] Wulfman C, Tezenas du Montcel S, Jonas P, Fattouh J, Rignon-Bret C. Aesthetic demand of French seniors: a largescale study. Gerodontology 2010; 27(4):266-71. https://doi.org/10.1111/j.1741-2358.2009.00331.x

[13] Satoh Y, Nagai E, Azaki M, Morikawa M, Ohyama T, Toyoma H, et al. Study on high-strength plastic teeth. J Nihon Univ Sch Dent 1993; 35(3):192-9. https://doi.org/10.2334/josnusd 1959.35.192

[14] Alessi PJ. CIE 15: Technical Report: Colorimetry, 3rd edition 2004. Available from: https://cielab.xyz/pdf/cie.15.2004\%20colorimetry.pdf. [Accessed on June 9, 2020].

[15] Commission Internationale de l'Eclairage. CIE Technical Report: Colorimetry. CIE Pub No. 15.3. Vienna: CIE Central Bureau; 2004.

[16] Acar O, Yilmaz B, Altintas SH, Chandrasekaran I, Johnston WM. Color stainability of CAD/CAM and nanocomposite resin materials. J Prosthet Dent 2016; 115(1):71-5. https://doi.org/10.1016/j.prosdent.2015.06.014

[17] Abu-Obaid A, AlMawash A, Alyabis N, Alzaaqi N. An in vitro evaluation of the effect of polishing on the stainability of different CAD/CAM ceramic materials. Saudi Dent J 2020; 32(3):135-41. https://doi.org/10.1016/j.sdentj.2019.08.005

[18] Dirxen C, Blunck U, Preissner S. Clinical performance of a new biomimetic double network material. Open Dent J 2013; 7(1):118-22. https://doi.org/10.2174/1874210620130904003

[19] Awad D, Stawarczyk B, Liebermann A, Ilie N. Translucency of esthetic dental restorative CAD/CAM materials and composite resins with respect to thickness and surface roughness. J Prosthet Dent 2015; 113(6):534-40. https://doi.org/10.1016/j.prosdent.2014.12.003

[20] Bottino M, Campos F, Ramos N, Rippe M, Valandro L, Melo R. Inlays made from a hybrid material: adaptation and bond strengths. Oper Dent 2015; 4O(3):E83-91. https://doi.org/10.2341/13-343-L

[21] Seghi RR, Hewlett E, Kim J. Visual and instrumental colorimetric assessments of small color differences on translucent dental porcelain. J Dent Res 1989; 68(12):1760-4. https://doi.org/10.1177/00220345890680120801

[22] Saba DA, Salama RA, Haridy R. Effect of different beverages on the color stability and microhardness of CAD/CAM hybrid versus feldspathic ceramic blocks: An in-vitro study. Future Dent J 2017; 3(2):61-6. https://doi.org/10.1016/j.fdj.2017.07.001

[23] Lawson NC, Burgess JO. Gloss and stain resistance of ceramic-polymer CAD/CAM restorative blocks. J Esthet Restor Dent 2016; 28(suppl 1):S40-5. https://doi.org/10.1111/jerd.12166

[24] Koksal T, Dikbas I. Color stability of different denture teeth materials against various staining agents. Dent Mater J 2008; 27(1):139-44. https://doi.org/10.4012/dmj.27.139

[25] Gawriołek M, Sikorska E, Ferreira LF, Costa AI, Khmelinskii I, Krawczyk A, et al. Color and luminescence stability of selected dental materials in vitro. J Prosthodont 2012; 21(2):112-22. https://doi.org/10.1111/j.1532849X.2011.00808.x

[26] Ghahramanloo A, Madani A, Sohrabi K, Sabzevari S. An evaluation of color stability of reinforced composite resin compared with dental porcelain in commonly consumed beverages. J Calif Dent Assoc 2008; 36(9):673-80.

[27] Al-Wahadni A, Muir Martin D. Glazing and finishing dental porcelain: a literature review. J Can Dent Assoc 1998; 64(8):580-3. 
[28] Özarslan MM, Büyükkaplan UŞ, Barutcigil Ç, Arslan M, Türker N, Barutcigil K. Effects of different surface finishing procedures on the change in surface roughness and color of a polymer infiltrated ceramic network material. J Adv Prosthodont 2016; 8(1):16-20. https://doi.org/10.4047/jap.2016.8.1.16

[29] Özarslan MM, Büyükkaplan UŞ, Barutcigil Ç, Özarslan M, Barutcigil K, Türker N. Assessing staining resistance of a $\mathrm{CAD} / \mathrm{CAM}$ interpenetrating network composite material. Head Face Med 2018; 14(1):1-7. https://doi.org/10.1186/s13005-018-0184-2

[30] Ward M, Tate W, Powers J. Surface roughness of opalescent porcelains after polishing. Oper Dent 1995; 20(3):10610.

[31] Esquivel JF, Chia J, Wozniak WT. Color stability of low-fusing porcelains for titanium. Int J Prosthodont, 1995; $8(5): 479-85$.

[32] Omata Y, Uno S, Nakaoki Y, Tanaka T, Sano H, Yoshida S, et al. Staining of hybrid composites with coffee, oolong tea, or red wine. Dent Mater J 2006; 25(1):125-31. https://doi.org/10.4012/dmj.25.125

[33] Türker SB, Kocak A, Aktepe E. Effect of five staining solutions on the colour stability of two acrylics and three composite resins based provisional restorations. Eur J Prosthodont Restor Dent 2006; 14(3):121-5. 